\title{
The Stratospheric Pathway of La Niña
}

\author{
MAdDALEN IZA AND NATAlia CAlvo \\ Departamento de Física de la Tierra II, Universidad Complutense de Madrid, \\ Madrid, Spain \\ ELISA MANZINI \\ Max Planck Institute for Meteorology, Hamburg, Germany
}

(Manuscript received 18 March 2016, in final form 31 August 2016)

\begin{abstract}
A Northern Hemisphere (NH) polar stratospheric pathway for La Niña events is established during wintertime based on reanalysis data for the 1958-2012 period. A robust polar stratospheric response is observed in the NH during strong La Niña events, characterized by a significantly stronger and cooler polar vortex. Significant wind anomalies reach the surface, and a robust impact on the North Atlantic-European (NAE) region is observed. A dynamical analysis reveals that the stronger polar stratospheric winds during La Niña winters are due to reduced upward planetary wave activity into the stratosphere. This finding is the result of destructive interference between the climatological and the anomalous La Niña tropospheric stationary eddies over the Pacific-North American region.

In addition, the lack of a robust stratospheric signature during La Niña winters reported in previous studies is investigated. It is found that this is related to the lower threshold used to detect the events, which signature is consequently more prone to be obscured by the influence of other sources of variability. In particular, the occurrence of stratospheric sudden warmings (SSWs), partly linked to the phase of the quasi-biennial oscillation, modulates the observed stratospheric signal. In the case of La Niña winters defined by a lower threshold, a robust stratospheric cooling is found only in the absence of SSWs. Therefore, these results highlight the importance of using a relatively restrictive threshold to define La Niña events in order to obtain a robust surface response in the NAE region through the stratosphere.
\end{abstract}

\section{Introduction}

El Niño-Southern Oscillation (ENSO) is the main source of interannual variability in the tropics with relevant teleconnections in the Northern Hemisphere (NH) extratropics (Horel and Wallace 1981). The stratospheric signal during the warm ENSO phase (El Niño) has been extensively documented (García-Herrera et al. 2006; Manzini et al. 2006; Fletcher and Kushner 2011); during EI Niño winters, upward wave activity toward the stratosphere is enhanced through constructive interference between the El Niño anomalies and the climatological eddies, resulting in a warmer and a weaker polar vortex. Related zonal mean zonal wind

Corresponding author address: Maddalen Iza, Departamento de Física de la Tierra II, Facultad de Ciencias Físicas, Universidad Complutense de Madrid, Plaza Ciencias, Avda. Complutense s/n, Ciudad Universitaria, 28040 Madrid, Spain.

E-mail:m.iza@ucm.es anomalies in the stratosphere propagate downward into the troposphere, having an impact on the North Atlantic and European (NAE) region (Cagnazzo and Manzini 2009; Ineson and Scaife 2009; Bell et al. 2009). It has been indeed shown that El Niño has the potential to improve seasonal predictability over Europe (Domeisen et al. 2015).

Less attention has been paid to the stratospheric response to the cold ENSO phase (La Niña), and it is not clear yet whether La Niña can affect the NAE region through a stratospheric pathway. Some studies based on reanalysis and observational data have shown a polar stratospheric cooling during La Niña winters, although the response is either weak or not significant (Mitchell et al. 2011; Free and Seidel 2009). It should be noted that the short record (and thus small signal-to-noise ratio) could be perhaps the reason for the absence of an evident robust stratospheric La Niña response in observations and reanalysis data. For this reason, a relatively low threshold is sometimes used to increase the number 
of identified La Niña events (Butler and Polvani 2011; Barriopedro and Calvo 2014; Domeisen et al. 2015). The different thresholds used to select cold ENSO events in the literature hamper a direct comparison among these studies. Thus, the polar stratospheric response and consequently its downward propagation to the troposphere during La Niña are still uncertain.

Here, we make use of a slightly longer reanalysis dataset than previously used to assess the NH stratospheric pathway of La Niña. We first use a relatively high La Niña threshold to investigate whether La Niña winters can lead to a robust response in the polar stratosphere distinguishable from the climatological state and whether a La Niña stratospheric pathway of influence into the troposphere is detectible. Thereafter, we explore the sensitivity of La Niña stratospheric signal to the threshold used to identify the events. Concerning the La Niña stratospheric pathway of influence into the troposphere, we recall that a close linkage between La Niña winters and the NAE region has already been found. Negative sea level pressure (SLP) anomalies are observed north of $50^{\circ} \mathrm{N}$ in late winter during La Niña events (Moron and Gouirand 2003), together with a strong precipitation anomaly pattern over the European region (PozoVázquez et al. 2005). This pattern, characterized by enhanced precipitation over Great Britain and Scandinavia and reduced precipitation over the southwestern Mediterranean area, is related to a positive phase of the North Atlantic Oscillation (NAO). However, Pozo-Vázquez et al. (2005) acknowledged that they could not provide a physical explanation for the relationship between cold ENSO events and the improvement on European climate predictability (via a positive NAO-like pattern). We will show that these linkages are consistent with a La Niña stratospheric pathway of influence to the troposphere.

In addition, by testing the sensitivity of La Niña signals on the selection threshold, we will shed light on the question of whether La Niña surface impact in the NAE region is modulated by other sources of variability, such as the stratospheric sudden warmings (SSWs) and the quasi-biennial oscillation (QBO). As Butler and Polvani (2011) stated, in the reanalysis record the SSW frequency of occurrence is enhanced, with respect to neutral winters, during both El Niño and La Niña winters. At the same time, the ENSO response is also influenced by the QBO (Garfinkel and Hartmann 2007, 2008; Calvo et al. 2009; Richter et al. 2015). For La Niña winters during the easterly QBO (EQBO) phase, an anomalous stratospheric temperature increase is observed in early winter, while a nonrobust signal is observed during La Niña winters under westerly QBO (WQBO) conditions (Garfinkel and Hartmann 2007). Likewise, the occurrence of SSWs can also be modulated by the QBO, as SSW occurrence could be favored during EQBO winters (McIntyre 1982), and delayed to mid- and late winter under WQBO conditions ( $\mathrm{Lu}$ et al. 2008). Therefore, within a short record and by using a low threshold, the interference with the SSWs and QBO signals could lead to an uncertain La Niña response.

\section{Methods}

\section{a. Event detection}

To characterize La Niña signal, first we need to establish the criterion to identify La Niña events. Several indices have been used in the literature, considering different oceanic regions, such as Niño-3 (N3) $\left(5^{\circ} \mathrm{N}-5^{\circ} \mathrm{S}\right.$, $150^{\circ}-90^{\circ} \mathrm{W}$ ) (Hoerling et al. 1997; Manzini et al. 2006) or Niño-4 (N4) $\left(5^{\circ} \mathrm{N}-5^{\circ} \mathrm{S}, 160^{\circ} \mathrm{E}-150^{\circ} \mathrm{W}\right)$ (Kug and Ham 2011; Zhang et al. 2015). However, most recent studies used the Niño-3.4 (N3.4) $\left(5^{\circ} \mathrm{N}-5^{\circ} \mathrm{S}, 170^{\circ}-120^{\circ} \mathrm{W}\right)$ index from the National Centers for Environmental Prediction/Climate Prediction Center (NCEP/CPC) (e.g., Free and Seidel 2009; Butler and Polvani 2011; Garfinkel et al. 2012; Butler et al. 2014; Barriopedro and Calvo 2014; Domeisen et al. 2015). For this reason, we choose the N3.4 index from the NCEP/CPC. In addition, these indices have been computed using sea surface temperature (SST) anomalies (e.g., Butler and Polvani 2011; Garfinkel et al. 2012) or their standardized values (e.g., Hoerling et al. 1997; Mitchell et al. 2011). Finally, different thresholds have been applied to select the events. Some studies selected La Niña events below $-0.5^{\circ} \mathrm{C}$ (Domeisen et al. 2015) or -0.7 standard deviations (SD) (Pozo-Vázquez et al. 2005), while other studies applied higher thresholds of -1 SD (Mitchell et al. 2011) or $-1 \mathrm{~K}$ (Free and Seidel 2009). As discussed in the introduction, the use of unequal thresholds could lead to a diverse range of responses.

To address this issue, we define La Niña winters by the standardized November-December-January-February (NDJF) SST anomalies, from the ERSSTV4 dataset and for the 1958-2012 climatological period, considering two thresholds: -1 and -0.5 SD. La Niña events selected below $-1 \mathrm{SD}$ will be referred to as strong La Niña events (8 events), whereas the events identified below $-0.5 \mathrm{SD}$ will be named extended La Niña events (20 events). Table 1 lists the La Niña winters identified by both thresholds. For comparison, we included the winters identified by Free and Seidel (2009) and Butler and Polvani (2011), who used thresholds of -1 and $-0.5^{\circ} \mathrm{C}$, respectively. The comparison shows that for the same period, the use of SST anomalies or their SD does not change the La Niña winter selection (see Table 1).

Major SSWs are identified using the criteria defined by Charlton and Polvani (2007). The central dates of the SSWs that occurred during La Niña winters are listed in 
TABLE 1. La Niña winters selected in this study, for -1- and -0.5-SD thresholds. La Niña winters identified by Free and Seidel (2009) and Butler and Polvani (2011). For each work the used thresholds and analysis periods are indicated along with SSW central dates and QBO phase.

\begin{tabular}{|c|c|c|c|c|c|}
\hline \multicolumn{4}{|c|}{ La Niña winters } & \multirow[b]{2}{*}{ SSW dates } & \multirow[b]{2}{*}{ QBO phase } \\
\hline $\begin{array}{c}-1 \mathrm{SD} \\
(1958-2012)\end{array}$ & $\begin{array}{l}\text { Free and Seidel (2009): } \\
\quad-1 \mathrm{~K}(1958-2005)\end{array}$ & $\begin{array}{c}-0.5 \mathrm{SD} \\
(1958-2012)\end{array}$ & $\begin{array}{l}\text { Butler and Polvani (2011): } \\
\quad-0.5^{\circ} \mathrm{C}(1958-2010)\end{array}$ & & \\
\hline - & - & $1962 / 63$ & $1962 / 63$ & $30 \mathrm{Jan}$ & - \\
\hline - & - & $1964 / 65$ & $1964 / 65$ & - & W \\
\hline - & - & $1967 / 68$ & $1967 / 68$ & 7 Jan & W \\
\hline $1970 / 71$ & 1970/71 & $1970 / 71$ & $1970 / 71$ & $18 \mathrm{Jan} / 20 \mathrm{Mar}$ & $\mathrm{E}$ \\
\hline - & - & $1971 / 72$ & $1971 / 72$ & - & W \\
\hline $1973 / 74$ & $1973 / 74$ & $1973 / 74$ & $1973 / 75$ & - & W \\
\hline - & - & $1974 / 75$ & $1974 / 75$ & - & $\mathrm{E}$ \\
\hline $1975 / 76$ & $1975 / 76$ & $1975 / 76$ & $1975 / 76$ & - & W \\
\hline - & - & $1983 / 84$ & $1983 / 84$ & $24 \mathrm{Feb}$ & - \\
\hline- & - & $1984 / 85$ & $1984 / 85$ & $1 \mathrm{Jan}$ & $\mathrm{E}$ \\
\hline $1988 / 89$ & $1988 / 89$ & $1988 / 89$ & $1988 / 89$ & $21 \mathrm{Feb}$ & W \\
\hline - & - & $1995 / 96$ & $1995 / 96$ & - & W \\
\hline $1998 / 99$ & $1998 / 99$ & $1998 / 99$ & $1998 / 99$ & $15 \mathrm{Dec} / 26 \mathrm{Feb}$ & $\mathrm{E}$ \\
\hline $1999 / 2000$ & $1999 / 2000$ & $1999 / 2000$ & $1999 / 2000$ & $20 \mathrm{Mar}^{\mathrm{a}}$ & W \\
\hline - & - & $2000 / 01$ & $2000 / 01$ & $11 \mathrm{Feb}$ & - \\
\hline - & - & $2005 / 06$ & $2005 / 06$ & $21 \mathrm{Jan}$ & $\mathrm{E}$ \\
\hline $2007 / 08$ & - & $2007 / 08$ & 2007/08 & $22 \mathrm{Feb}$ & $\mathrm{E}$ \\
\hline- & - & $2008 / 09$ & $2008 / 09$ & $24 \mathrm{Jan}$ & $\mathrm{W}$ \\
\hline $2010 / 11$ & - & $2010 / 11$ & - & - & W \\
\hline- & - & $2011 / 12$ & - & - & W \\
\hline
\end{tabular}

${ }^{a}$ Owing to the SSW late winter occurrence, for this study's purposes, this winter is considered as a winter without SSWs.

Table 1 . These central dates agree with those found by Nishii et al. (2011) and Taguchi (2016), using the same Japanese reanalysis. Differences across reanalyses on SSW detection are already documented (Charlton and Polvani 2007; Palmeiro et al. 2015) and do not alter our results (not shown). The QBO phase is evaluated using the $5^{\circ} \mathrm{S}-5^{\circ} \mathrm{N}$ average zonal mean zonal wind at $50 \mathrm{hPa}$, which is close to the most favorable level to find the link with the NH identified by Baldwin and Dunkerton (1998). Following the definition used by Butler et al. (2016), westerly (easterly) QBO phases are classified when the zonal mean zonal wind in November is above $5 \mathrm{~m} \mathrm{~s}^{-1}$ (below $-5 \mathrm{~m} \mathrm{~s}^{-1}$ ) (stated in Table 1).

\section{b. Data and analysis}

This study analyzes monthly mean and daily data from the Japanese 55-year Reanalysis (JRA-55) (Kobayashi et al. 2015), from the Japan Meteorological Agency. The data are distributed in a horizontal grid of $2.5^{\circ} \times 2.5^{\circ}$ (latitude $\times$ longitude), with 37 vertical pressure levels, ranging from 1000 to $1 \mathrm{hPa}$. Monthly mean time series of precipitation and surface temperature at high resolution $\left(0.5^{\circ} \times 0.5^{\circ}\right.$ grid $)$ are obtained from the University of East Anglia Climatic Research Unit (CRU) time series (TS) 3.21 dataset (Harris et al. 2014). Time series for each field are detrended and the anomalous fields are computed with respect to the total climatology from
1958 to 2012, and then anomalies are composited for the identified La Niña events.

To investigate the polar stratospheric response, the December-January-February (DJF) average is computed, whereas the November-December-January (NDJ) average is used to analyze the preceding mechanisms. The surface impact is analyzed in January-February, when the largest signals are observed. To study the downward propagation of the signal the standardized northern annular mode (NAM) index is computed by projecting daily geopotential height anomalies onto the first empirical orthogonal function (EOF) of the 60-day low-pass geopotential height anomaly $\left(20^{\circ}-90^{\circ} \mathrm{N}\right)$. The statistical significance (when indicated) is assessed with a Monte Carlo test of 1000 trials, in which random groups of the same number of years as those in the composites are chosen from the entire 55-yr period. Anomalies are considered significant with respect to the climatology at the $90 \%$ and $95 \%$ confidence levels. A Student's $t$ test is also applied to compare meridional eddy heat flux terms.

\section{Results}

\section{a. La Niña stratospheric pathway}

In this section, the response to strong La Niña events (those identified using the -1-SD threshold) is analyzed. Figure 1 shows the latitude-pressure DJF average of the 
a) Tbar (8)

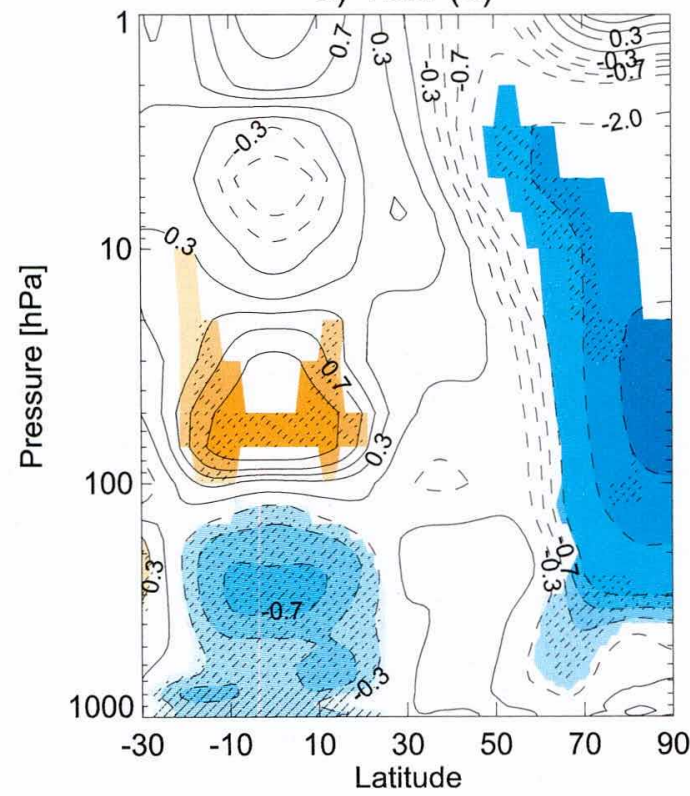

b) Ubar (8)

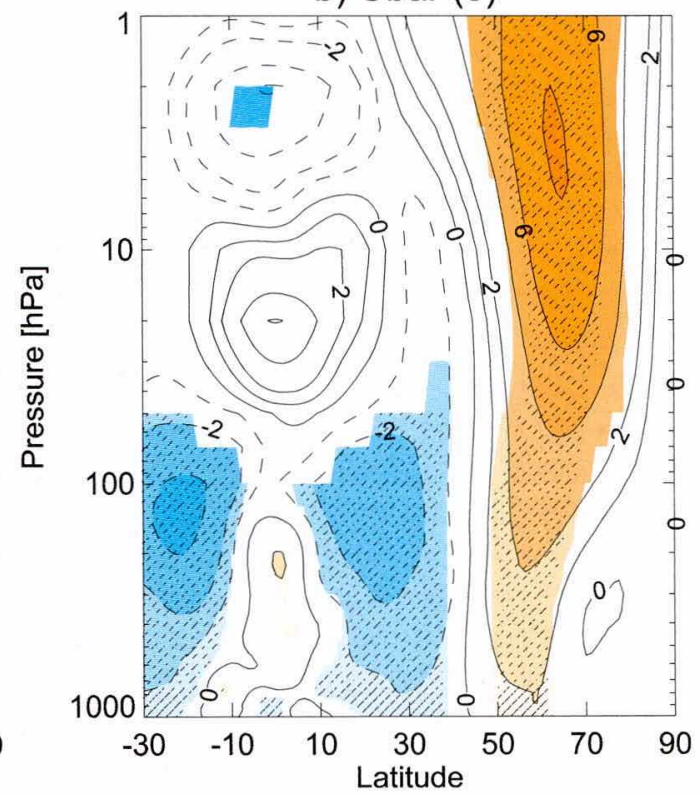

FIG. 1. Latitude-pressure cross sections of the composite of DJF average of monthly zonal mean (a) temperature and (b) zonal wind anomalies for strong La Niña events (-1-SD threshold). Contour intervals for temperature are $\pm 0.3,0.5$, and $0.7 \mathrm{~K}$ up to $\pm 1 \mathrm{~K}$ and every $1 \mathrm{~K}$ thereafter. Contours for zonal wind are $\pm 1 \mathrm{~m} \mathrm{~s}^{-1}$ up to $\pm 2 \mathrm{~m} \mathrm{~s}^{-1}$ and every $2 \mathrm{~m} \mathrm{~s}^{-1}$ thereafter. Solid (dashed) contours denote positive (negative) anomalies. Numbers in brackets indicate the number of winters in each composite. Colors indicate areas significant at the $90 \%$ confidence level, and stippling indicates significance at the $95 \%$ level.

zonal mean temperature (Fig. 1a) and zonal mean zonal wind (Fig. 1b) composited for strong La Niña events. In the tropics, La Niña signal is characterized by an anomalous significant cooling (about $-0.7 \mathrm{~K}$ ) in the troposphere and anomalous significant warming in the lower stratosphere. These anomalies in temperature are accompanied by a significant weakening of the subtropical jets. In the high latitudes, a significant cooling (peaking at about $-3 \mathrm{~K}$ ) appears in the stratosphere (from about 300 to $10 \mathrm{hPa}$ ) together with a robust strengthening of the zonal mean zonal winds that extends into the troposphere and reaches the surface. The observed significant temperature pattern was also reproduced in model simulations by Calvo et al. (2010). Robust results hold for the NCEP-NCAR (Kalnay et al. 1996) and ERA (ERA-40 for 1958-78 and ERA-Interim for 1979-2012) (Uppala et al. 2005; Dee et al. 2011) reanalyses for the same period (not shown).

The identified significant stratospheric zonal mean temperature and wind anomalies are indicative of a strong and cold polar vortex, whose evolution through the winter is depicted in Fig. 2, averaged from $70^{\circ}$ to $90^{\circ} \mathrm{N}$ for the former and $50^{\circ}$ to $70^{\circ} \mathrm{N}$ for the latter. Detailed inspection of Fig. 2 reveals a downward propagation of the anomalies from the upper stratosphere in early winter to the lowermost stratosphere and the troposphere in late winter (January-February). The large- scale character of the anomalies is demonstrated by the zonal mean zonal wind significant anomalies (Fig. 2b), which reach the surface in January and February, in thermal wind balance with the temperature patterns. Figure 2 also shows the evolution of the NAM index, which is a compact measure of the vortex strength (Baldwin and Dunkerton 2001) and stratospheretroposphere coupling. The NAM index (Fig. 2c) shows significant positive values (red colors) reflecting a strong vortex, which is amplified in the lower stratosphere and shows a temporal development in line with the temperature and wind anomalies (Figs. 2a,b).

In summary, a robust polar stratospheric response, in the form of a stronger and colder polar vortex that reaches the surface is observed during strong La Niña events. It is interesting to note that our results are based on a data record that includes two more events (the latest two events of 2007/08 and 2010/11 winters) than previous studies (Free and Seidel 2009; Mitchell et al. 2011), which did not find a robust signal in the polar lower stratosphere and the troposphere even though they used the same threshold $(-1 \mathrm{SD})$. Therefore, with the caution of a still short dataset and the sampling uncertainty, we suggest that the use of a longer dataset helps to capture a significant stratospheric signal in strong La Niña winters. In fact, the studies that reported a surface signal over Europe for La Niña analyzed near 100-yr 

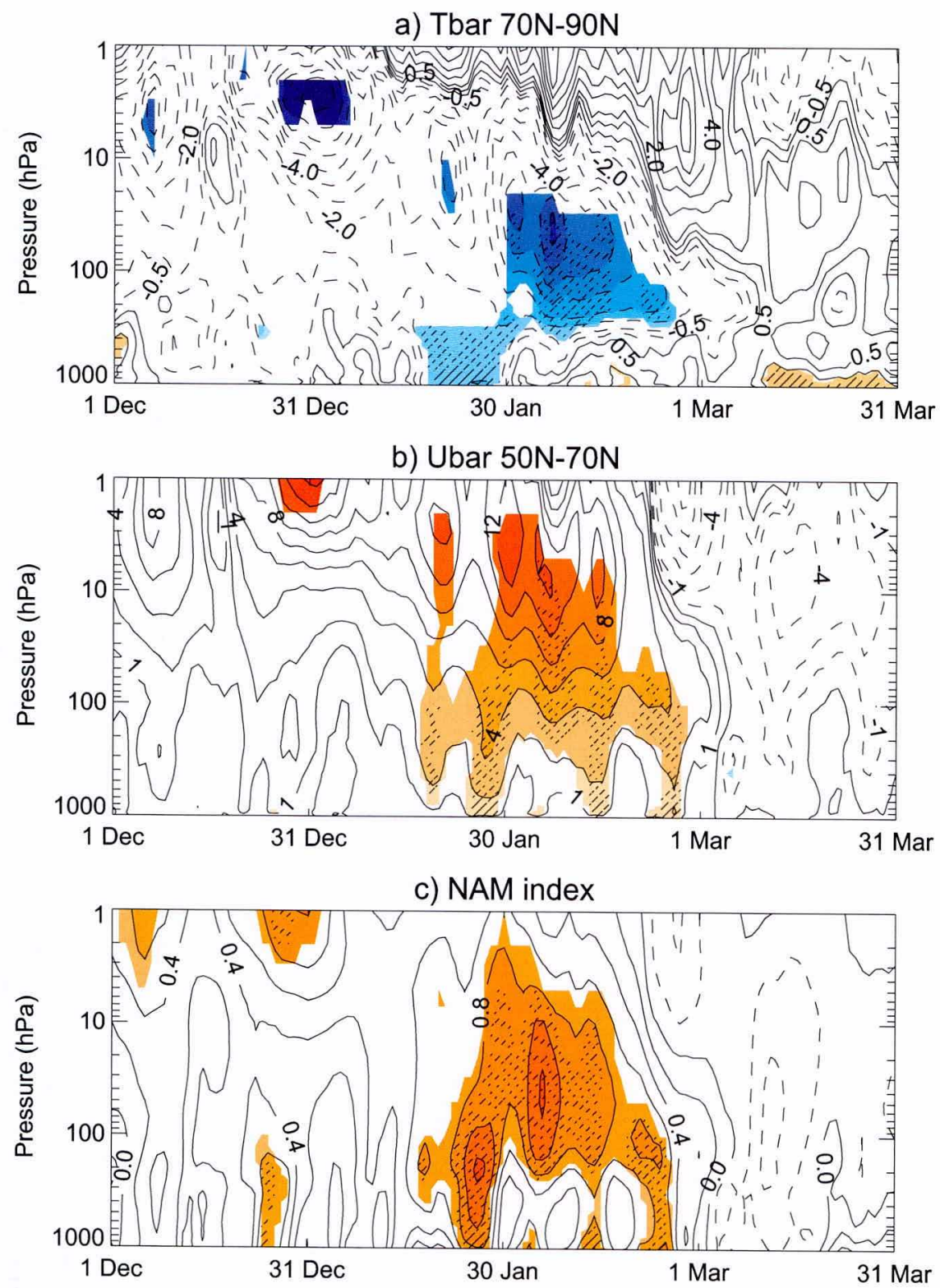

FIG. 2. Composites of time-pressure December-March evolution daily zonal mean of (a) temperature anomalies at $70^{\circ}-90^{\circ} \mathrm{N}$, (b) zonal wind anomalies at $50^{\circ}-70^{\circ} \mathrm{N}$, and (c) NAM index (contour interval: 0.2 ) for strong La Niña winters (-1-SD threshold). Contour intervals for temperature are $\pm 0.5 \mathrm{~K}$ up to $\pm 1 \mathrm{~K}$ and every $1 \mathrm{~K}$ thereafter. Contours for zonal wind are $\pm 1 \mathrm{~m} \mathrm{~s}^{-1}$ up to $\pm 2 \mathrm{~m} \mathrm{~s}^{-1}$ and every $2 \mathrm{~m} \mathrm{~s}^{-1}$ thereafter. Solid (dashed) contours denote positive (negative) anomalies. Colors indicate areas significant at the $90 \%$ confidence level, and stippling indicates significance at the $95 \%$ level.

periods (Moron and Gouirand 2003; Pozo-Vázquez et al. 2005).

Accordingly, the surface impact of the identified stratospheric response over the Arctic and the NAE region is illustrated in Fig. 3, for the January-February average, when the largest signal at the surface was observed (Fig. 2). The Arctic region displays negative SLP anomalies while positive SLP anomalies appear over the NAE region
(Fig. 3a). Anomalies are about $-8 \mathrm{hPa}$ over the Icelandic low and $4 \mathrm{hPa}$ over the Azores high, resembling a positive NAO phase. Notably, these anomalies are of the same order (but opposite in sign) to those found in response to El Niño events by Cagnazzo and Manzini (2009) in reanalysis data. Consistent with the SLP anomalies, a significant anomalous warming is observed at the surface over northern and central Europe (Fig. 3b). Its largest value 
a) SLP

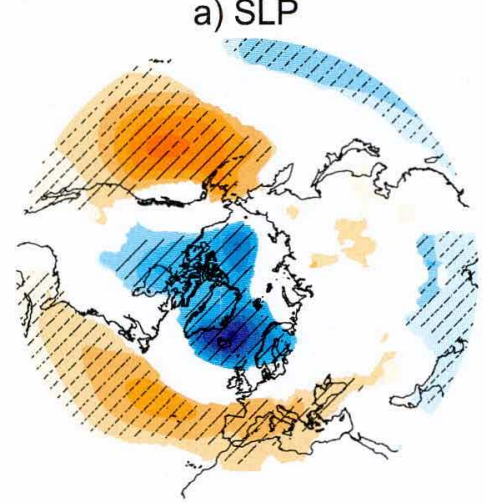

$[\mathrm{hPa}]$

$\begin{array}{lllllllllllllllllllll}-11-10 & -9 & -8 & -7 & -6 & -5 & -4 & -3 & -2 & -1 & 0 & 1 & 2 & 3 & 4 & 5 & 6 & 7 & 8 & 9 & 10\end{array}$

\section{b) Temperature (CRU)}
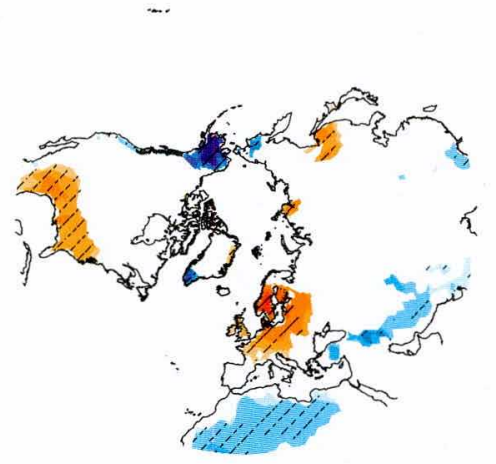

$[\mathrm{K}]$

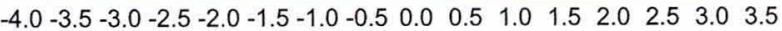

c) Precipitation (CRU)

$\cdots$

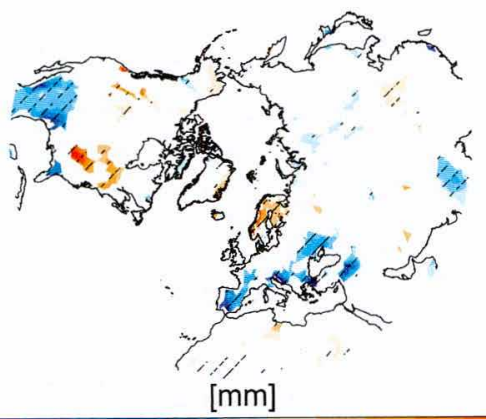

$\begin{array}{llllllllllllllll}-40 & -35 & -30 & -25 & -20 & -15 & -10 & -5 & 0 & 5 & 10 & 15 & 20 & 25 & 30 & 35\end{array}$

FIG. 3. Longitude-latitude polar projection composite of the January-February average (a) SLP, (b) surface temperature, and (c) precipitation for strong La Niña winters. Colors indicate areas significant at the $90 \%$ confidence level, and stippling indicates significance at the $95 \%$ level.
$(3 \mathrm{~K})$ is reached over Scandinavia. The positive NAO-like pattern is related to a decrease in precipitation over the Mediterranean region and increased precipitation over Scandinavia (Fig. 3c). The pattern in precipitation is similar to that found by Pozo-Vázquez et al. (2005), who already related it to La Niña events and a positive NAO phase. The novelty of our study is that we reveal the role of the stratosphere in the NH La Niña winter response. Hence, our results indicate that strong La Niña events could be as useful as El Niño events to improve wintertime seasonal predictability over Europe.

\section{b. Dynamical mechanisms}

Now that we have shown the robust La Niña response in the polar stratosphere and in the NAE region, next we address the dynamical mechanisms that lead to these signals. In the lower stratosphere temperature is mainly dominated by planetary wave dissipation that deposit momentum modulating the mean flow and the mean meridional circulation (Newman et al. 2001; Edmon et al. 1980). The Eliassen-Palm (EP) flux and its divergence are measurements of planetary wave propagation and dissipation, respectively (Andrews et al. 1987). Figure 4a shows the NDJ climatology (19582012) of the EP flux (arrows) and EP flux divergence (colors). Planetary waves propagate upward and are refracted toward the equator in the upper stratosphere. The negative values of the EP flux divergence indicate the regions where the atmospheric planetary waves deposit zonal momentum. During strong La Niña events, an anomalously downward EP flux is observed in the troposphere between $40^{\circ}$ and $60^{\circ} \mathrm{N}$ and throughout the entire stratosphere between $60^{\circ}$ and $90^{\circ} \mathrm{N}$ (Fig. 4b). The anomalies in the EP flux divergence are positive in the stratosphere and exceed $0.5 \mathrm{~m} \mathrm{~s}^{-1}$ day $^{-1}$ in the upper region. These results indicate that during strong La Niña winters, the climatological upward wave propagation and dissipation is reduced in the polar stratosphere, which leads to a stronger polar vortex as shown in Figs. 1 and 2. This behavior in the wave-mean flow interaction during La Niña was already shown in a model experiment (Li and Lau 2013), but this is the first time it is found in reanalysis data.

To provide further insight into the mechanism related to the lack of wave activity penetrating into the stratosphere, we focus on the zonal mean eddy meridional heat flux, which is the main contributor to the vertical component of the EP flux (Newman et al. 2001). Following the framework of Nishii et al. (2009) we decomposed the anomalous zonal mean meridional eddy heat flux:

$$
\left\langle\left. v^{*} T^{*}\right|_{a}\right\rangle=\left\langle v_{a}^{*} T_{c}^{*}+v_{c}^{*} T_{a}^{*}\right\rangle+\left\langle\left. v_{a}^{*} T_{a}^{*}\right|_{a}\right\rangle
$$



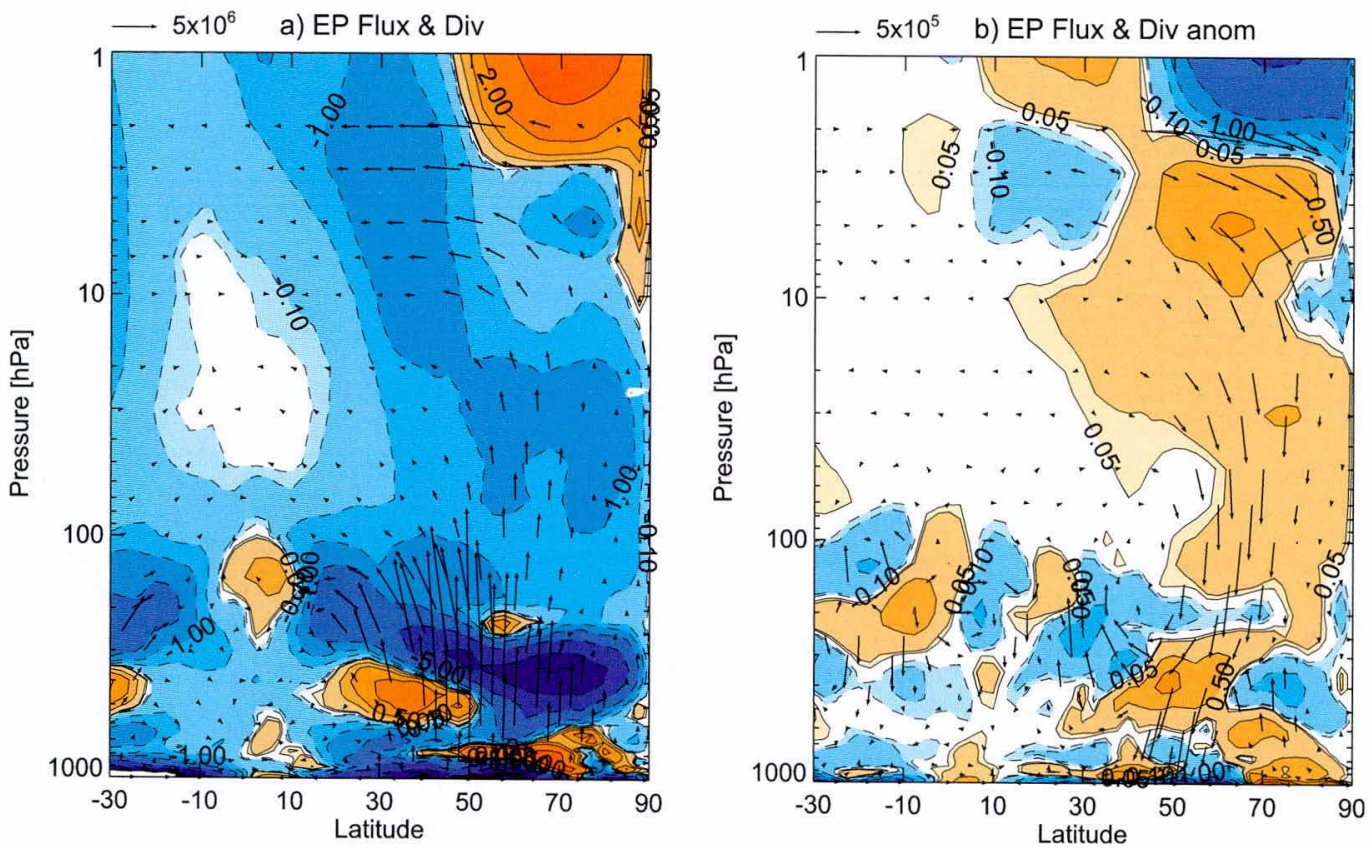

FIG. 4. Latitude-pressure cross sections of the NDJ average of the EP flux (arrows) and EP flux divergence (contours) (a) climatology and (b) anomalies for strong La Niña winters. Contours are drawn at $\pm 0.05,0.1,0.5,1,2$, $5,10,15$, and $20 \mathrm{~m} \mathrm{~s}^{-1} \mathrm{day}^{-1}$. Arrow scale is shown at the top left for (a) $5 \times 10^{6}$ and (b) $5 \times 10^{5} \mathrm{~kg} \mathrm{~s}^{-2}$.

Similar notation to that of Nishii et al. (2009) has been used. Thus, the asterisks denote the deviation from the zonal mean (the eddy) for the meridional wind $v$ and the temperature $T$, and the angled brackets $<$.> denote the composite mean. The subscripts $c$ and $a$ stand for the climatology and the daily anomaly. The first term on the right-hand side corresponds to the interference term that accounts for the interference between the climatological stationary waves and the anomalous waves. The second term is the anomalous wave packet term, and it reflects the activity of the anomalous wave itself. Figure 5 shows the total anomalous meridional eddy heat flux at $100 \mathrm{hPa}$ for the NDJ mean averaged between $45^{\circ}$ and $75^{\circ} \mathrm{N}$ composited for strong La Niña (gray) and neutral (yellow) winters (Fig. 5a). Its decomposition into the interference and anomalous wave packet terms appears in Figs. 5b and 5c, respectively. The corresponding values are summarized in Table 2. Neutral winters are defined as winters with no El Niño or La Niña events. In this case, we have chosen the threshold of $0.5 \mathrm{SD}$ for $\mathrm{El}$ Niño and -0.5 SD for La Niña in the N3.4 region to make sure neutral years do not include any ENSO signal. For both strong La Niña and neutral winters, the anomalous meridional heat flux is negative (Fig. 5a), indicating that in both cases the upward wave activity is reduced compared to the climatology, as was already shown in Fig. 4. However, the magnitude of the total anomalous heat flux is much larger during La Niña winters than in neutral winters ( -0.96 against $-0.16 \mathrm{~m} \mathrm{~K} \mathrm{~s}^{-1}$ ).
Interestingly, the decomposition into different terms reveals the contribution of different factors during neutral and strong La Niña winters. During strong La Niña winters, the interference term $\left(-0.88 \mathrm{~m} \mathrm{~K} \mathrm{~s}^{-1}\right)$ accounts for $92 \%$ of the anomalous eddy heat flux, and this interference term is statistically different to the same term during neutral winters at the $90 \%$ confidence level according to a $t$ test. For neutral winters, unlike La Niña winters, the total anomalous meridional eddy heat flux term is dominated $(73 \%)$ by the anomalous wave packet term. Thus, strong La Niña winters are characterized by a large reduction in upward wave activity through destructive interference between the anomalous planetary waves and the climatological eddies.

Nishii et al. (2010) investigated the polar stratospheric response associated with the western Pacific teleconnection and reported destructive interference between the anomalous wave and the climatology prior to a polar stratospheric cooling. They also found that this destructive interference was mainly dominated by the term $v_{a}^{*} T_{c}^{*}$ in Eq. (1). In particular, Nishii et al. (2010) showed that the climatological warm eddy temperature $T_{c}^{*}$ and the equatorward eddy meridional wind anomalies $v_{a}^{*}$ over the Bering Sea and Alaska at $100 \mathrm{hPa}$ contributed negatively to the anomalous meridional eddy heat flux. Also during strong La Niña winters the term $v_{a}^{*} T_{c}^{*}$ in Eq. (1) is the main contributor to the interference term (not shown). Then, we have reproduced the analysis made by Nishii et al. (2010) for strong La Niña 
a) $\left[V^{*} T^{*}\right]$ a $100 \mathrm{hPa}$ NDJ days

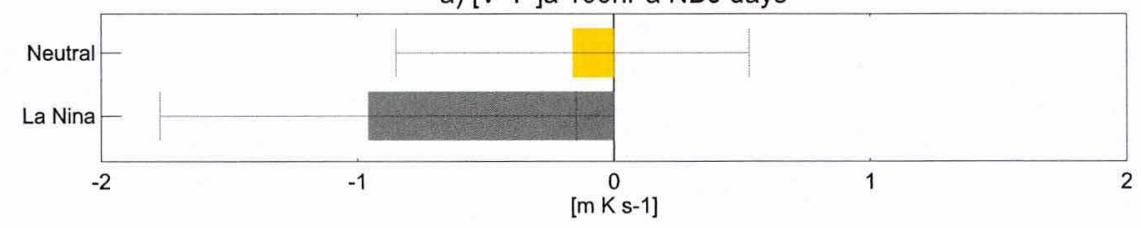

b) $\left[\mathrm{Vc}^{\star} \mathrm{Ta}^{\star}+\mathrm{Va}^{\star} T \mathrm{c}^{\star}\right] 100 \mathrm{hPa}$ NDJ days

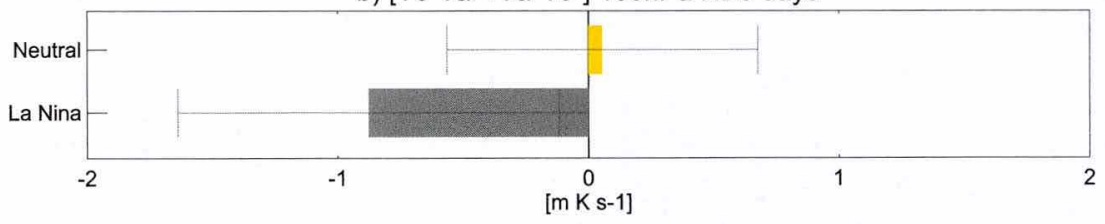

c) $\left[\mathrm{Va}^{*} \mathrm{Ta}^{*}\right] \mathrm{a} 100 \mathrm{hPa}$ NDJ days

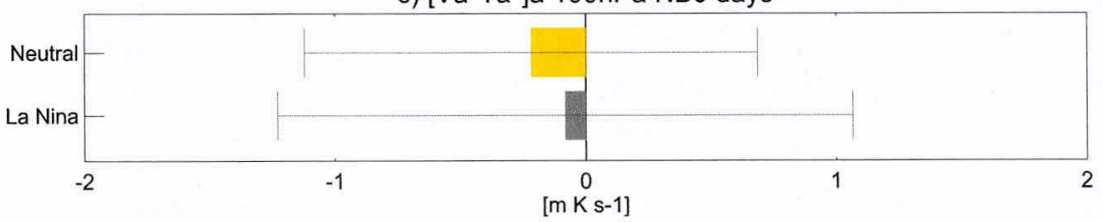

FIG. 5. The 100-hPa (a) total anomalous meridional eddy heat flux response and (b) the contribution of interference and (c) anomalous wave packet terms for neutral (yellow) and strong La Niña (gray) winters, for NDJ days mean, averaged between $45^{\circ}$ and $75^{\circ} \mathrm{N}$. Error bars indicate the lower and upper confidence limit for the mean at the $95 \%$ confidence interval.

winters, and Fig. 6a shows $T_{c}^{*}$ and $v_{a}^{*}$ at $100 \mathrm{hPa}$. During strong La Niña winters, prior to a polar stratospheric cooling, the anomalous eddy meridional wind is equatorward (negative values) over Alaska and the Bering Sea region, where the eddy temperature is climatologically warm, similar to Nishii et al. (2010) results. Such anomalous interference is associated with the tropospheric wave pattern in eddy geopotential height anomalies, whose average for NDJ is shown in Fig. 6b. A dipole of anomalies is observed over the northeast Pacific and North America, in quadrature to that during El Niño winters (Hoerling et al. 1997). The dipole, with the node over the ocean, is characterized by significant negative anomalies over North America and large significant positive anomalies over the North Pacific Ocean. These positive anomalies extend toward the northwest Pacific leading to a weak Aleutian low, in agreement with the behavior that Nishii et al. (2010) found preceding a polar cooling.

In summary, the analysis carried out here explains the origin of the stratospheric pathway presented in the previous section by consistent dynamical mechanisms. During strong La Niña winters an anomalous weak Aleutian low leads to suppressed anomalous upward wave activity into the stratosphere, via destructive interference between the anomalous and climatological stationary waves, which in turn strengthens the stratospheric polar vortex.

\section{c. Sensitivity to La Niña threshold}

The results presented here raise the question of why previous studies did not find similar robust responses. We already mentioned in the introduction that the use

TABLE 2. Total anomalous meridional eddy heat flux terms and the decomposition into interference and anomalous wave packet terms in $\left(\mathrm{m} \mathrm{K} \mathrm{s}^{-1}\right)$ units for neutral winters, strong La Niña winters (-1-SD threshold), strong La Niña winters with SSWs, strong La Niña winters without SSWs, extended La Niña winters ( -0.5 -SD threshold), extended La Niña winters with SSWs, and extended La Niña winters without SSWs.

\begin{tabular}{lrrr}
\hline \hline \multicolumn{1}{c}{ Winters } & Total & Interference term & Anomalous wave packet term \\
\hline Neutral & -0.16 & 0.06 & -0.22 \\
Strong La Niña & -0.96 & -0.88 & -0.08 \\
Strong La Niña SSW & -1.16 & -0.72 & -0.44 \\
Strong La Niña, no SSW & -0.75 & -1.03 & 0.28 \\
Extended La Niña & -0.18 & -0.29 & 0.11 \\
Extended La Niña SSW & 0.55 & 0.09 & 0.46 \\
Extended La Niña, no SSW & -1.07 & -0.75 & -0.32 \\
\hline
\end{tabular}


a) $\mathrm{Va}^{*} \& \mathrm{Tc}^{*} 100 \mathrm{hPa}$

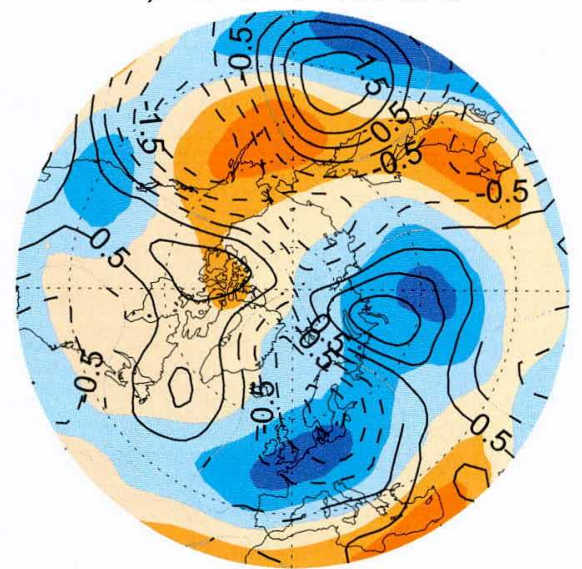

$[\mathrm{K}]$

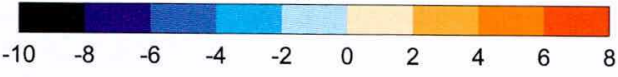

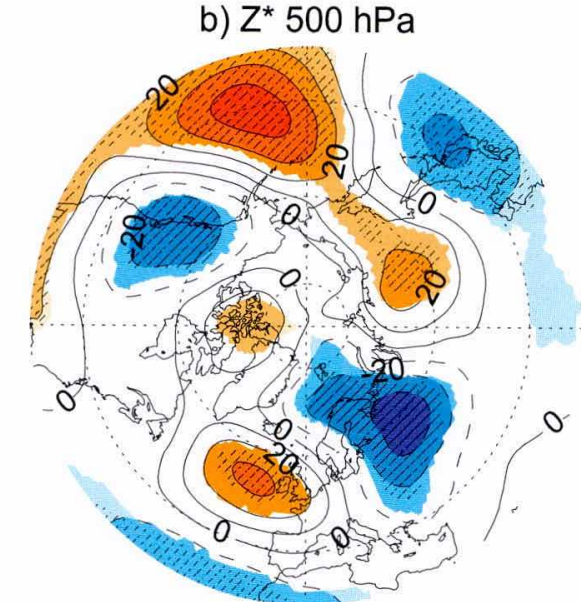

[m]

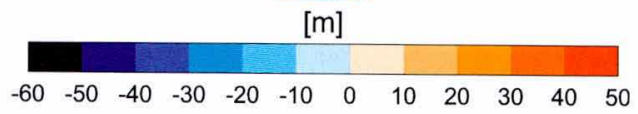

FIG. 6. Longitude-latitude polar projection composite of strong La Niña winters (NDJ average). (a) Eddy meridional wind anomalies (contour intervals: $0.5 \mathrm{~m} \mathrm{~s}^{-1}$ ) and climatological eddy temperature (colors) at $100 \mathrm{hPa}$. For wind fields solid (dashed) contours denote positive (negative) values. Black lines (gray lines) indicate significant (nonsignificant) eddy meridional wind anomalies at the $90 \%$ confidence level. (b) Eddy geopotential height anomalies at $500 \mathrm{hPa}$. Solid (dashed) contours denote positive (negative) anomalies. Colors indicate areas significant at the $90 \%$ confidence level, and stippling indicates significance at the $95 \%$ level. Longitude grids are depicted every $90^{\circ}$ (from $\left.0^{\circ} \mathrm{E}\right)$ and latitude grids every $20^{\circ}\left(\right.$ from $\left.40^{\circ} \mathrm{N}\right)$.

of a lower threshold is a common methodology that has been followed in other studies to allow for a larger composite size. Next, we investigate the relevance of the threshold in obtaining a robust response to La Niña events. To do so, we define extended La Niña events whenever the standardized SST anomalies (SSTA) over the N3.4 region are below $-0.5 \mathrm{SD}$ (the events are listed in Table 1). Figure 7 shows the scatterplots of the standardized NDJF SSTA Niña-3.4 index versus the DJF zonal mean zonal wind anomalies at $10 \mathrm{hPa}$ for the $50^{\circ}$ and $70^{\circ} \mathrm{N}$ average (Fig. 7a) and the DJF polar cap temperature anomalies between $70^{\circ}$ and $90^{\circ} \mathrm{N}$ at $50 \mathrm{hPa}$
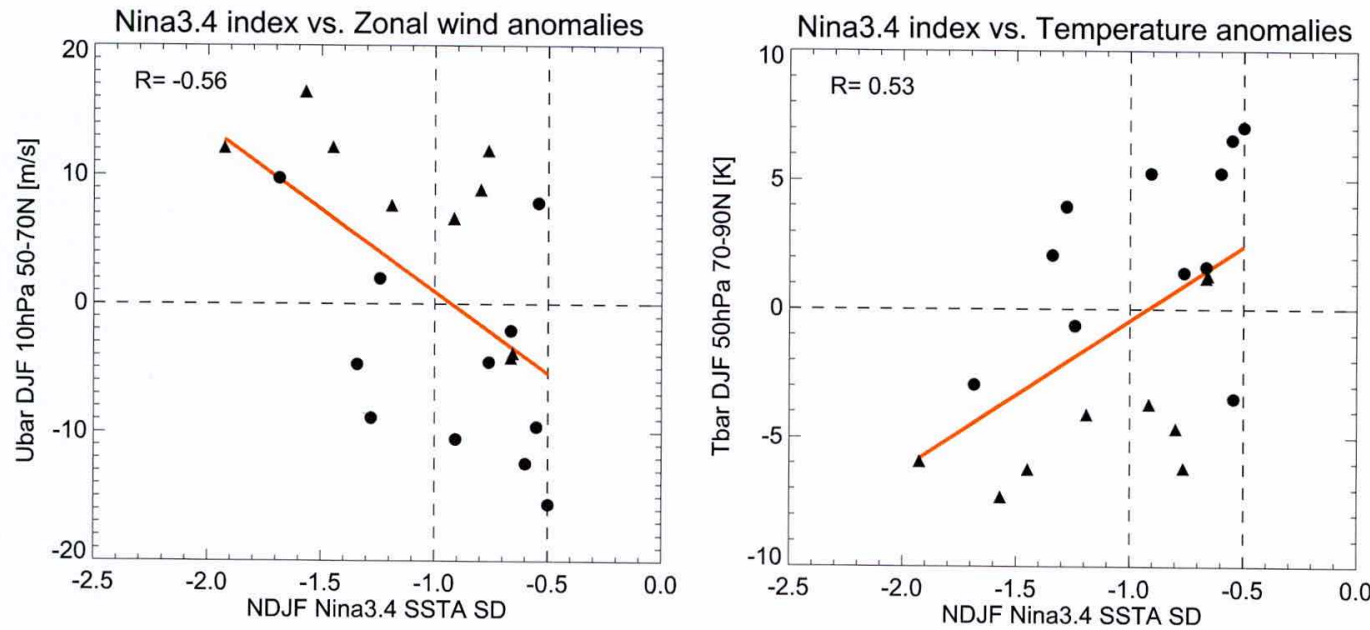

FIG. 7. Scatterplots of the standardized NDJF SSTA Niña-3.4 index vs (a) the $50^{\circ}-70^{\circ} \mathrm{N}$ DJF zonal mean zonal wind anomalies at $10 \mathrm{hPa}$ and (b) the $70^{\circ}-90^{\circ} \mathrm{N}$ DJF zonal mean temperature anomalies at $50 \mathrm{hPa}$. In each scatterplot the red line indicates the linear fit for the La Niña events below $-0.5 \mathrm{SD}$, and the vertical dashed lines denote the -1 - and -0.5 -SD thresholds used to identify La Niña events. The correlation coefficient is noted in the upper-left corner of each scatterplot. Winters with at least one SSW are plotted with dots, and winters without SSWs are plotted with triangles. 

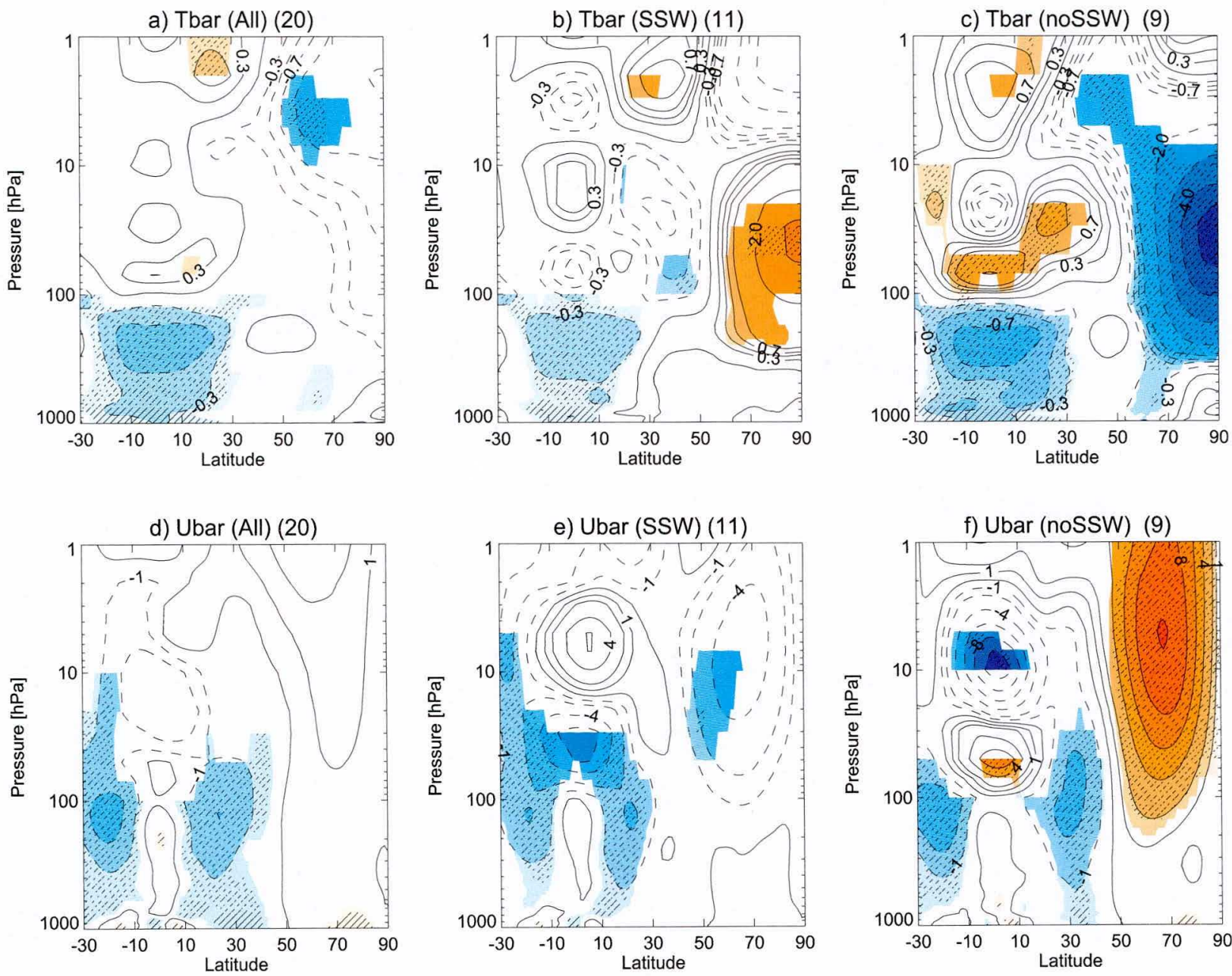

FIG. 8. As in Fig. 1, but for (a).(d) extended La Niña winters (-0.5-SD threshold), (b),(e) extended La Niña winters with SSWs, and (c),(f) extended La Niña winters without SSWs (see Table 1 for details). Numbers in brackets indicate the number of winters in each composite.

(Fig. 7b). A clear relationship between the extended La Niña events SST anomalies and the polar stratospheric response is observed. The correlation coefficient between the extended La Niña index and the DJF zonal mean zonal wind anomalies is $r=-0.56$, suggesting that the stronger the La Niña events, the stronger the polar vortex. Correspondingly, the correlation coefficient for the temperature is $r=0.53$; that is, the stronger the $\mathrm{La}$ Niña events, the colder the stratospheric anomalies. A similar correlation coefficient is obtained for strong $\mathrm{La}$ Niña events, comparable to the coefficients obtained by Free and Seidel (2009) for both ENSO phases. Importantly, Fig. 7 shows that the linear fit crosses over zero very close to the -1 -SD threshold, supporting the use of the $-1-\mathrm{SD}$ threshold to define strong La Niña winters.

Figure 8 (left) shows the latitude-pressure composite of extended La Niña winters for the DJF zonal mean temperature (Fig. 8a) and zonal mean zonal wind
(Fig. 8d), similar to Fig. 1. Not surprisingly, the magnitude of the tropospheric cooling at the equator is slightly weaker in the composite of extended La Niña winters than in strong La Niña events $(-0.5$ vs $-0.7 \mathrm{~K})$. Differences are also observed in the lowermost tropical stratosphere, where the warming is substantially smaller and not significant in the extended La Niña winters. Likewise, in the polar stratosphere the zonal mean responses in temperature and zonal wind are much weaker and not significant, in agreement with previous studies that used the same threshold. Therefore, these results suggest that the -0.5 -SD threshold is not adequate to extract the La Niña response in the stratospheric circulation. This interpretation agrees with the scatterplot results (Fig. 7) since weaker events show a larger spread for the stratospheric response. This might be because the extended La Niña events are simply not strong enough to generate a polar stratospheric response or 
$\left[\mathrm{Va}^{\star} T \mathrm{c}^{*}+\mathrm{Vc}^{\star} \mathrm{Ta}^{\star}\right]$ 100hPa NDJ days

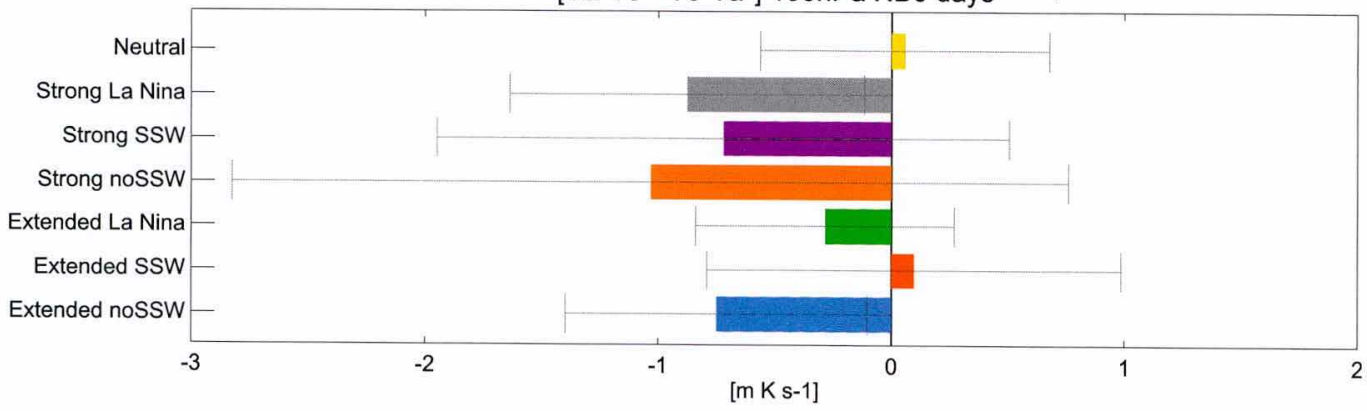

FIG. 9. NDJ mean total anomalous meridional eddy heat flux interference contribution at $100 \mathrm{hPa}$ and averaged between $45^{\circ}$ and $75^{\circ} \mathrm{N}$ for neutral winters (yellow), strong La Niña winters (gray; -1-SD threshold), strong La Niña winters with SSWs (purple), strong La Niña winters without SSWs (brown), extended La Niña winters (green; -0.5-SD threshold), extended La Niña winters with SSWs (orange), and extended La Niña winters without SSWs (blue). Error bars indicate the lower and upper confidence limit for the mean at the $95 \%$ confidence interval.

because even though they are able to modulate the polar stratosphere, their weaker signals are masked by other sources of variability. We next investigate the latter possibility. The major disruption of the polar stratosphere comes from the occurrence of SSWs. To investigate the role of SSWs on La Niña response, we separate the extended La Niña winters in those with and without SSWs (Fig. 7). It is remarkable that winters with SSWs (dots) are mostly related to negative wind and warm temperature anomalies, whereas winters without SSWs (triangles) are linked to stronger wind and cold temperature anomalies. The frequencies of winters with at least one SSW (between November and February) are similar for strong and extended La Niña winters, 0.50 and 0.55 , respectively. The composited zonal mean temperature and zonal mean zonal wind anomalies for the extended La Niña winters with and without SSWs are shown in Fig. 8. Similar results are obtained when the anomalies are computed with respect to a climatology based exclusively on winters without SSW occurrence (not shown). During extended La Niña winters with SSWs (Figs. 8b,e), a significant warming is observed in the lower polar stratosphere accompanied by negative zonal mean zonal winds. This behavior is opposite to that shown during strong La Niña events (Fig. 1) and reflects the occurrence of the SSWs. In contrast, when extended La Niña winters without SSWs are composited (Figs. 8c,f) a robust cooling and significant positive zonal wind anomalies appear in the polar stratosphere, similar to the pattern obtained for strong La Niña events (Fig. 1). Note that the magnitude of the anomalies is even larger than that in Fig. 1 ( -5 vs $-3 \mathrm{~K}$ and 10 vs $\left.8 \mathrm{~m} \mathrm{~s}^{-1}\right)$. However, unlike strong La Niña events, significant zonal mean zonal wind anomalies do not penetrate into the troposphere. For comparison, we also stratified strong La Niña winters into winters with and without SSWs (not shown). Interestingly, the stratospheric response during strong La Niña winters with SSWs is not significant, probably related to the counteracting effects of the SSW-related warming and strong La Niña cooling on the small-sized composite (only four winters are composited in this case). As expected for strong La Niña winters without SSWs a strong significant cooling appears (about $-8 \mathrm{~K}$ ). Indeed, these strong events dominate also the signature of the extended La Niña events without SSWs (Figs. 8c,f) (not shown).

In the tropical troposphere, the cold signature observed for strong La Niña events is also present for the extended La Niña winters with and without SSWs (Figs. 8b,c), although during winters with SSWs this signal is weaker and the anomalous cooling does not reach $-0.5 \mathrm{~K}$ (Fig. $8 \mathrm{~b}$ ). In fact, the composite of the standardized SST anomalies in the N3.4 region during extended La Niña events with SSWs is $-1 \mathrm{SD}$, which is lower and statistically different from the -1.46-SD value, obtained for extended La Niña winters without SSWs. Thus, the tropical Pacific SST anomalies are on average weaker for the extended La Niña events with SSWs than for those without SSWs. Still, in both cases the tropical response in the troposphere is an anomalous cooling, which cannot explain by itself the opposite signs found in the polar stratosphere during extended La Niña events with or without SSWs. Hence, it is clear that SSWs play a relevant role in modulating the observed polar stratospheric signal for extended La Niña winters, which, we claim, is characterized by a robust cooling.

To better understand the role of the SSWs during La Niña winters, Fig. 9 extends Fig. 5b, by including the interference term for extended La Niña events and strong and extended La Niña winters with and without SSWs. The extended La Niña events (green) show a negative but small interference contribution (Table 2), not statistically different compared to neutral winters (yellow), in line with Sassi et al.'s (2004) results using a 
model simulation. The division of extended La Niña winters into winters with and without SSWs provides additional information. During extended La Niña winters without SSWs the interference term is negative (blue), indicative of reduced upward wave activity and similar to that during strong La Niña winters $(-0.75$ vs $-0.88 \mathrm{~m} \mathrm{~K} \mathrm{~s}^{-1}$; no statistical differences are found). Instead, during extended La Niña winters with SSWs (orange), the interference contribution to the anomalous heat flux is positive, reflecting anomalous upward wave activity in this case. On the contrary, for strong La Niña winters selected with $-1-S D$ threshold, the interference term is negative for winters with and without SSWs (purple and brown). This indicates destructive interference regardless of the SSW occurrence, albeit the reduced composite size introduces widespread error bars. However, the contribution of the interference and anomalous wave packet terms to the total anomalous heat flux is very different during the extended La Niña winters with and without SSWs. While the interference term (destructive interference) dominates during extended La Niña winters without SSWs (see Table 2), similar to the behavior found during strong La Niña winters, the contribution of the anomalous wave packet term is larger in the case of extended La Niña winters with SSWs (Table 2). This is consistent with the analysis of Smith and Kushner (2012), who found that the interference term was more important in composites with lower heat flux values (strong La Niña and extended La Niña events without SSWs in our case). To sum up, La Niña signal is related to destructive interference between the climatological and anomalous planetary waves. However, a constructive interference takes place when SSWs occur, supporting our hypothesis that the polar stratospheric signal observed during extended La Niña events with SSWs reflects the behavior of the SSWs.

To add consistency to our conclusions we plot the interference terms and geopotential height anomalies (analogous to Fig. 6) for extended La Niña winters with and without SSWs (Fig. 10). During extended La Niña winters with SSWs (Fig. 10a) the anomalous meridional eddy wind over Alaska and the Bering Sea region is poleward (positive values), while it is equatorward during extended La Niña winters without SSWs (Fig. 10b), leading to constructive and destructive interference, respectively. Differences are also found in tropospheric eddy geopotential height anomalies. During extended La Niña winters without SSWs (Fig. 10d) an anomalous dipole, similar to that found during strong La Niña winters (Fig. 6), is observed, although the positive anomalies extend more to the northwest and are weaker. During extended La Niña winters with SSWs (Fig. 10c), the dipole is shifted eastward; positive anomalies are confined to lower latitudes and do not reach the Bering Sea and Alaska region. Indeed, Garfinkel et al. (2012) identified this region (near $62^{\circ} \mathrm{N}$ and $180^{\circ} \mathrm{E}$ ) as a precursor of SSWs, such that negative geopotential height anomalies were detected therein prior to the occurrence of SSWs leading to a weaker vortex. The interference of the negative geopotential height anomalies before the SSWs together with the positive anomalies associated with La Niña winters (Fig. 10c) results in nonsignificant anomalies in this region. Therefore, the lack of a polar stratospheric response during extended La Niña winters could be related to a sampling problem, as the signal-to-noise ratio is largely reduced due to the occurrence of SSWs.

In addition to the influence of SSWs, inspection of the zonal mean zonal wind anomalies in the tropics reveals that the QBO could be also playing a role on modulating the stratospheric signal during extended La Niña winters. During extended La Niña winters with SSWs, Fig. 8e shows easterly wind anomalies at the equator between 20 and $60 \mathrm{hPa}$, while westerlies are observed during La Niña winters without SSWs (Fig. 8f). Table 1 shows the QBO phase for each extended La Niña winter. We identify 6 EQBO winters (5 of them with SSWs) and 11 WQBO winters ( 3 of them with SSWs). This means that SSWs occur in $83 \%$ of the EQBO winters, and they are absent in $73 \%$ of the WQBO winters. Note that three extended La Niña winters are unclassified. Thus, there seems to be a relationship between extended La Niña winters with SSWs and the EQBO phase and extended La Niña winters without SSWs and WQBO. Dunkerton et al. (1988) already noted that SSWs are not prone to occur during the WQBO phase. However, the percentages we obtained during extended La Niña winters are reduced when we consider the entire 55 winters: SSWs (no SSWs) occur in the $61 \%(61 \%)$ of the EQBO (WQBO) phase winters. Similar to the subsetting performed in Fig. 8, the classification of extended La Niña winters into EQBO and WQBO phases also depicts significant and opposite polar stratospheric anomalies (not shown), but such EQBO/WQBO division is closely related to the SSW occurrence/absence. Unfortunately, the limited reanalysis record hampers a deeper analysis on the relationship between SSWs and QBO phases during La Niña winters. Nonetheless, we can determine that the SSWs-/QBO-induced modulations of the polar vortex are strong enough to hide $\mathrm{La}$ Niña signal when a low threshold is selected $(-0.5 \mathrm{SD})$. On the other hand, the polar stratospheric response to strong La Niña events ( $-1 \mathrm{SD})$ is robust, even though the signal in the tropical stratosphere is weakly positive, suggesting a weak WQBO predominance (Fig. 1b), but 

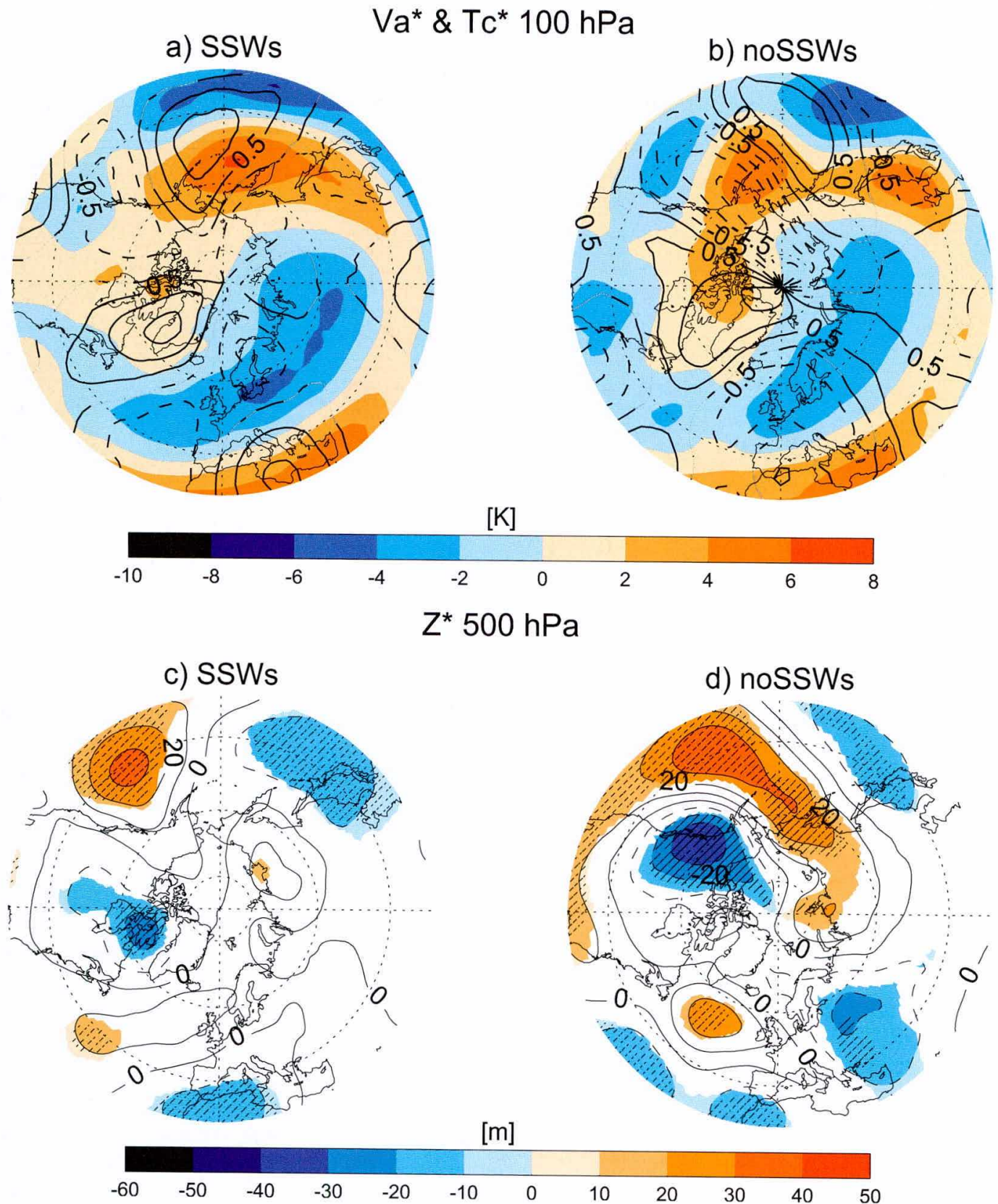

FIG. 10. As in Fig. 6, but for (a),(c) extended La Niña winters with SSWs and (b),(d) extended La Niña winters without SSWs.

it is not statistically significant. In fact, the classification of strong La Niña events into EQBO and WQBO phase winters suggests, despite the limited sample, no predominance of the QBO signal over the strong La Niña stratospheric signature (not shown).

\section{Summary and discussion}

This study reveals a stratospheric pathway for La Niña and its teleconnections in the NAE region, using the
JRA-55 reanalysis and the CRU dataset. With 55 years of reanalysis data we have found a significant strong and cold polar stratospheric vortex during strong La Niña events. These events are defined as those with an NDJF N3.4 index lower than -1 SD. These zonal mean stratospheric anomalies are later on propagated downward, from the upper stratosphere in late December to the troposphere in January-February, when they reach the surface. The consequent surface impact presents a robust pattern of negative SLP anomalies over the 
Arctic and positive anomalies over the NAE region. These anomalies increase the advection of warm air from the North Atlantic Ocean to Europe, and thus an anomalous warming is detected in northern and central Europe while reduced precipitation is observed in the Mediterranean area and enhanced precipitation over Scandinavia. Our analysis also reveals the mechanism behind this pathway. A significant anomalously weak Aleutian low is observed during strong La Niña events and prompts destructive interference between the climatological and the anomalous La Niña stationary waves. This in turn leads to reduced upward-propagating wave activity into the stratosphere and weaker wave forcing, strengthening the polar vortex. In short, we have established a stratospheric link between the tropospheric anomalies in the tropics and anomalies in the NAE region during strong La Niña winters. Consequently, distinct but analogous to El Niño, our results suggest that strong La Niña events (defined by the -1 -SD threshold) could be relevant to improve seasonal predictability over Europe.

Furthermore, we explain the lack of a robust La Niña response in the stratosphere reported in previous observational and reanalysis studies; the competing influences of SSW occurrence and the QBO during extended La Niña events (defined by the $-0.5-\mathrm{SD}$ threshold) lead to a nonsignificant response in the polar stratosphere. Thereafter, we conclude that a threshold of $-0.5 \mathrm{SD}$ in the N3.4 index is not appropriate to obtain the atmospheric teleconnections of La Niña. For this reason, we recommend defining La Niña events with a relatively high threshold of $-1 \mathrm{SD}$ on the N3.4 index. At the same time, we also noted that our longer dataset includes the two latest La Niña events, which were not considered before and are characterized by a midwinter strong polar stratospheric cooling.

On the relationship between La Niña events and the occurrence of SSWs, the frequencies of SSW occurrence per winter, defined from November to March, are 0.88 and 0.70 for strong and extended La Niña events (note that more than one SSW occurs during some La Niña winters). Such frequencies are similar to El Niño winter SSW frequency (0.76) and higher than for the neutral winters $(0.44)$. Then, we did not report a reduced SSW occurrence frequency during La Niña winters compared to El Niño or neutral winters, in agreement with the study of Butler and Polvani (2011). However, it is remarkable that strong La Niña events selected in this study are mainly related to late winter SSW occurrence. During strong La Niña winters, five out of the seven SSWs registered occurred late in winter (beyond 20 February). Instead, during the extended La Niña winters only one additional SSW is found late in winter (see Table 1). These results suggest that the reduced upward wave activity related to strong La Niña events might not inhibit but delay to late winter the occurrence of SSWs. Nonetheless, owing to the short reanalysis record, this hypothesis needs to be investigated in the future in long model simulations.

Compared to previous studies based on reanalysis, it is important to notice that our results suggest a stratospheric pathway that does not reconcile with the one defined by Butler et al. (2014). While Butler et al. (2014) consider the stratospheric pathway active only when one or more SSW occurs, we searched for a stratospheric pathway for La Niña, irrespective of SSW occurrence, and we found that La Niña is associated with a strong vortex, which can also have an impact at the surface (Baldwin and Dunkerton 2001). In addition, we found discrepancies in the detection of strong La Niña events compared to those in Mitchell et al. (2011), who also used reanalysis data. Applying the -1-SD threshold, similar as we do for strong La Niña events, they impose the SSTA to exceed -1 SD for at least 3 months including December. In this fashion, they identified eight La Niña winters based on HadISST over the 1958-2002 period. However, according to our selection, based on NCEP/CPC N3.4 index and using a longer period to compute the climatology, two of those winters (1983/84 and 1984/85) cannot be identified as strong La Niña winters (their NDJF anomalies do not reach the -1-SD threshold). This means that they include some extended La Niña winters in their composites, and their significant signal is confined to the upper stratosphere (see Mitchell et al. 2011, their Fig. 6).

On the other hand, modeling studies on La Niña response in the polar stratosphere show contradictory results. The pioneer modeling works of Sassi et al. (2004) and Manzini et al. (2006) showed a negligible response to La Niña in the polar stratosphere, which was not statistically different from neutral winters. Nonetheless, more recent modeling studies reported a significant stratospheric cooling during La Niña (Calvo et al. 2010) and a robust strong vortex related to suppressed anomalous upward propagation ( $\mathrm{Li}$ and Lau 2013). None of these modeling studies investigated the possibility of a stratospheric effect over the NAE region, and given that our composites size is still reduced, it would be of interest to analyze the role of the stratosphere in $\mathrm{NH}$ tropospheric La Niña teleconnections in long model simulations. Moreover, such simulations would allow evaluating interactions among the different sources of variability detected here, such as the occurrence of SSWs and the QBO phase and their modulation on the NAE La Niña teleconnections. Finally, the potential of La Niña to improve seasonal predictions should also be tested in model simulations. 
Acknowledgments. We acknowledge the Japan Meteorological Agency for providing JRA-55 reanalysis data, the University of East Anglia Climatic Research Unit (CRU) for the TS3.21dataset, and the National Center for Environmental Prediction/Climate Prediction Center (NCEP/CPC) for the N3.4 index. M. I. and N. C. are supported by the Spanish Ministry of Economy and Competitiveness through the MATRES (CGL2012-34221) project and the European Project 603557 STRATOCLIM under Program FP7-ENV.2013.6.1-2. The authors are grateful to R. García-Herrera and D. Barriopedro for their helpful discussions and the editor and reviewers who helped improve the manuscript. This work was partially performed during a visit of M. I. at the Max Planck Institute for Meteorology, Hamburg, and M. I. acknowledges MPI-M for the support.

\section{REFERENCES}

Andrews, D. G., J. R. Holton, and C. B. Leovy, 1987: Middle Atmosphere Dynamics. International Geophysics Series, Vol. 40, Academic Press, 489 pp.

Baldwin, M. P., and T. J. Dunkerton, 1998: Quasi-biennial modulation of the Southern Hemisphere stratospheric polar vortex. Geophys. Res. Lett., 25, 3343-3346, doi:10.1029/98GL02445.

—, and —, 2001: Stratospheric harbingers of anomalous weather regimes. Science, 294, 581-584, doi:10.1126/science.1063315.

Barriopedro, D., and N. Calvo, 2014: On the relationship between ENSO, stratospheric sudden warmings, and blocking. J. Climate, 27, 4704-4720, doi:10.1175/JCLI-D-13-00770.1.

Bell, C. J., L. J. Gray, A. J. Charlton-Perez, M. M. Joshi, and A. A. Scaife, 2009: Stratospheric communication of El Niño teleconnections to European winter. J. Climate, 22, 4083-4096, doi:10.1175/2009JCLI2717.1.

Butler, A. H., and L. M. Polvani, 2011: El Niño, La Niña, and stratospheric sudden warmings: A reevaluation in light of the observational record. Geophys. Res. Lett., 38, L13807, doi:10.1029/2011GL048084.

, - - and C. Deser, 2014: Separating the stratospheric and tropospheric pathways of El Niño-Southern Oscillation teleconnections. Environ. Res. Lett., 9, 024014, doi:10.1088/ 1748-9326/9/2/024014.

—, and Coauthors, 2016: The climate-system historical forecast project: Do stratosphere-resolving models make better seasonal climate predictions in boreal winter? Quart. I. Roy. Meteor. Soc., 142, 1413-1427, doi:10.1002/qj.2743.

Cagnazzo, C., and E. Manzini, 2009: Impact of the stratosphere on the winter tropospheric teleconnections between ENSO and the North Atlantic and European region. J. Climate, 22, 12231238, doi:10.1175/2008JCLI2549.1.

Calvo, N., M. A. Giorgetta, R. Garcia-Herrera, and E. Manzini, 2009: Nonlinearity of the combined warm ENSO and QBO effects on the Northern Hemisphere polar vortex in MAECHAM5 simulations. J. Geophys. Res., 114, D13109, doi:10.1029/2008JD011445.

, R. R. Garcia, W. J. Randel, and D. R. Marsh, 2010: Dynamical mechanism for the increase in tropical upwelling in the lowermost tropical stratosphere during warm ENSO events. J. Atmos. Sci., 67, 2331-2340, doi:10.1175/2010JAS3433.1.
Charlton, A. J., and L. M. Polvani, 2007: A new look at stratospheric sudden warmings. Part I: Climatology and modeling benchmarks. J. Climate, 20, 449-469, doi:10.1175/JCLI3996.1.

Dee, D. P., and Coauthors, 2011: The ERA-Interim reanalysis: Configuration and performance of the data assimilation system. Quart. J. Roy. Meteor. Soc., 137, 553-597, doi:10.1002/qj.828.

Domeisen, D. I. V., A. H. Butler, K. Fröhlich, M. Bittner, W. A. Müller, and J. Baehr, 2015: Seasonal predictability over Europe arising from El Niño and stratospheric variability in the MPI-ESM seasonal prediction system. J. Climate, 28, 256-271, doi:10.1175/JCLI-D-14-00207.1.

Dunkerton, T. J., D. P. Delisi, and M. P. Baldwin, 1988: Distribution of major stratospheric warmings in relation to the quasibiennial oscillation. Geophys. Res. Lett., 15, 136-139, doi:10.1029/GL015i002p00136.

Edmon, H. J., Jr., B. J. Hoskins, and M. E. McIntyre, 1980: Eliassen-Palm cross sections for the troposphere. J. Atmos. Sci., 37, 2600-2616, doi:10.1175/1520-0469(1980)037<2600: EPCSFT $>2.0 . \mathrm{CO} ; 2$.

Fletcher, C. G., and P. J. Kushner, 2011: The role of linear interference in the annular mode response to tropical SST forcing. J. Climate, 24, 778-794, doi:10.1175/2010JCLI3735.1.

Free, M., and D. J. Seidel, 2009: Observed El Niño-Southern Oscillation temperature signal in the stratosphere. J. Geophys. Res., 114, D23108, doi:10.1029/2009JD012420.

García-Herrera, R., N. Calvo, R. R. Garcia, and M. A. Giorgetta, 2006: Propagation of ENSO temperature signals into the middle atmosphere: A comparison of two general circulation models and ERA-40 Reanalysis data. J. Geophys. Res., 111, D06101, doi:10.1029/2005JD006061.

Garfinkel, C. I., and D. L. Hartmann, 2007: Effects of the El NiñoSouthern Oscillation and the quasi-biennial oscillation on polar temperatures in the stratosphere. J. Geophys. Res., 112, D19112, doi:10.1029/2007JD008481.

—, and —, 2008: Different ENSO teleconnections and their effects on the stratospheric polar vortex.J. Geophys. Res., 113, D18114, doi:10.1029/2008JD009920.

- A. H. Butler, D. W. Waugh, M. M. Hurwitz, and L. M. Polvani, 2012: Why might stratospheric sudden warmings occur with similar frequency in El Niño and La Niña winters? J. Geophys. Res., 117, D19106, doi:10.1029/2012JD017777.

Harris, I., P. D. Jones, T. J. Osborn, and D. H. Lister, 2014: Updated high-resolution grids of monthly climatic observationsThe CRU TS3.10 dataset. Int. J. Climatol., 34, 623-642, doi:10.1002/joc.3711.

Hoerling, M. P., A. Kumar, and M. Zhong, 1997: El Niño, La Niña, and the nonlinearity of their teleconnections. J. Climate, 10, 1769-1786, doi:10.1175/1520-0442(1997)010<1769:ENOLNA > 2.0.CO;2.

Horel, J. D., and J. M. Wallace, 1981: Planetary-scale atmospheric phenomena associated with the Southern Oscillation. Mon. Wea. Rev., 109, 813-829, doi:10.1175/1520-0493(1981)109<0813: PSAPAW $>2.0 . \mathrm{CO} ; 2$.

Ineson, S., and A. A. Scaife, 2009: The role of the stratosphere in the European climate response to El Niño. Nat. Geosci., 2, 3236, doi:10.1038/ngeo381.

Kalnay, E., and Coauthors, 1996: The NCEP/NCAR 40-Year Reanalysis Project. Bull. Amer. Meteor. Soc., 77, 437-471, doi:10.1175/1520-0477(1996)077<0437:TNYRP>2.0.CO;2.

Kobayashi, S., and Coauthors, 2015: The JRA-55 Reanalysis: General specifications and basic characteristics. J. Meteor. Soc. Japan, 93, 5-48, doi:10.2151/jmsj.2015-001.

Kug, J.-S., and Y.-G. Ham, 2011: Are there two types of La Niña? Geophys. Res. Lett., 38, L16704, doi:10.1029/2011GL048237. 
Li, Y., and N.-C. Lau, 2013: Influences of ENSO on stratospheric variability, and the descent of stratospheric perturbations into the lower troposphere. J. Climate, 26, 4725-4748, doi:10.1175/ JCLI-D-12-00581.1.

Lu, H., M. P. Baldwin, L. J. Gray, and M. J. Jarvis, 2008: Decadalscale changes in the effect of the QBO on the northern stratospheric polar vortex. J. Geophys. Res., 113, D10114, doi:10.1029/2007JD009647.

Manzini, E., M. A. Giorgetta, M. Esch, L. Kornblueh, and E. Roeckner, 2006: The influence of sea surface temperatures on the northern winter stratosphere: Ensemble simulations with the MAECHAM5 model. J. Climate, 19, 3863-3881, doi:10.1175/JCLI3826.1.

McIntyre, M. E., 1982: How well do we understand the dynamics of stratospheric warmings? J. Meteor. Soc. Japan, 60, 37-65. [Available online at https://www.jstage.jst.go.jp/article/ jmsj1965/60/1/60_1_37/_pdf.]

Mitchell, D. M., L. J. Gray, and A. J. Charlton-Perez, 2011: The structure and evolution of the stratospheric vortex in response to natural forcings. J. Geophys. Res., 116, D15110, doi:10.1029/ 2011JD015788.

Moron, V., and I. Gouirand, 2003: Seasonal modulation of the El Niño-Southern Oscillation relationship with sea level pressure anomalies over the North Atlantic in October-March 1873-1996. Int. J. Climatol., 23, 143-155, doi:10.1002/joc.868.

Newman, P. A., E. R. Nash, and J. E. Rosenfield, 2001: What controls the temperature of the Arctic stratosphere during the spring? J. Geophys. Res., 106, 19999-20010, doi:10.1029/ 2000JD000061.

Nishii, K., H. Nakamura, and T. Miyasaka, 2009: Modulations in the planetary wave field induced by upward-propagating Rossby wave packets prior to stratospheric sudden warming events: A case-study. Quart. J. Roy. Meteor. Soc., 135, 39-52, doi:10.1002/qj.359.

,-- , and Y. J. Orsolini, 2010: Cooling of the wintertime Arctic stratosphere induced by the western Pacific teleconnection pattern. Geophys. Res. Lett., 37, L13805, doi:10.1029/ 2010 GL043551.

,-- , and —_, 2011: Geographical dependence observed in blocking high influence on the stratospheric variability through enhancement and suppression of upward planetarywave propagation. J. Climate, 24, 6408-6423, doi:10.1175/ JCLI-D-10-05021.1.

Palmeiro, F. M., D. Barriopedro, R. García-Herrera, and N. Calvo, 2015: Comparing sudden stratospheric warming definitions in reanalysis data. J. Climate, 28, 6823-6840, doi:10.1175/ JCLI-D-15-0004.1.

Pozo-Vázquez, D., S. R. Gámiz-Fortis, J. Tovar-Pescador, M. J. Esteban-Parra, and Y. Castro-Díez, 2005: El Niño-Southern Oscillation events and associated European winter precipitation anomalies. Int. J. Climatol., 25, 17-31, doi:10.1002/ joc.1097.

Richter, J. H., C. Deser, and L. Sun, 2015: Effects of stratospheric variability on El Niño teleconnections. Environ. Res. Lett., 10, 124021, doi:10.1088/1748-9326/10/12/124021.

Sassi, F., D. Kinnison, B. A. Boville, R. R. Garcia, and R. Roble, 2004: Effect of El Niño-Southern Oscillation on the dynamical, thermal, and chemical structure of the middle atmosphere. J. Geophys. Res., 109, D17108, doi:10.1029/ 2003JD004434.

Smith, K. L., and P. J. Kushner, 2012: Linear interference and the initiation of extratropical stratosphere-troposphere interactions. J. Geophys. Res., 117, D13107, doi:10.1029/ 2012JD017587.

Taguchi, M., 2016: Connection of predictability of major stratospheric sudden warmings to polar vortex geometry. Atmos. Sci. Lett., 17, 33-38, doi:10.1002/asl.595.

Uppala, S. M., and Coauthors, 2005: The ERA-40 Re-Analysis. Quart. J. Roy. Meteor. Soc., 131, 2961-3012, doi:10.1256/qj.04.176.

Zhang, W., L. Wang, B. Xiang, L. Qi, and J. He, 2015: Impacts of two types of La Niña on the NAO during boreal winter. Climate Dyn., 44, 1351-1366, doi:10.1007/s00382-014-2155-z. 
Copyright of Journal of Climate is the property of American Meteorological Society and its content may not be copied or emailed to multiple sites or posted to a listserv without the copyright holder's express written permission. However, users may print, download, or email articles for individual use. 